\title{
Highly efficient silica gel-supported 1,2-diaminocyclohexane-Pd catalyst for Suzuki-Miyaura and Sonogashira coupling reactions
}

\section{Shaheen M. Sarkar • Md. Nazmul Alam •}

Md. Rezwan Miah

Published online: 17 June 2009

(C) Akadémiai Kiadó, Budapest, Hungary 2009

\section{Erratum to: React Kinet Catal Lett (2009) 96(1):175-183 \\ DOI 10.1007/s11144-009-5456-1}

Scheme 1 is missing from the original published article.



1<smiles>CCOCCCNC1CCCCC1NCCCOCC</smiles>

2

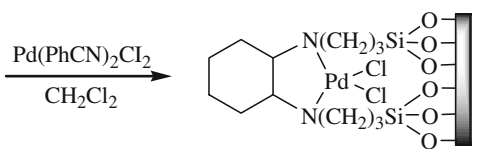

Scheme 1 Preparation of silica gel supported palladium catalyst 4

The online version of the original article can be found under doi:10.1007/s11144-009-5456-1.

\section{S. M. Sarkar}

Department of Chemical Engineering, Inha University, Incheon 402-751, South Korea

Md. N. Alam $(\bowtie) \cdot$ Md. R. Miah

Department of Chemistry, School of Physical Sciences, Shahjalal University of Science and Technology, Sylhet 3114, Bangladesh

e-mail: nazmul-che@sust.edu; nazmul_che@yahoo.com 